\title{
O PRINCÍPIO DA EFICIÊNCIA E AS CONTRATAÇÕES PÚBLICAS COM O TERCEIRO SETOR
}

\author{
THE PRINCIPLE OF EFFICIENCY AND PUBLIC CONTRACTING WITH THE THIRD SECTOR
}

\section{Letícia Beatriz de Oliveira de Souza*}

\section{Resumo:}

O presente artigo pretende tratar dos novos instrumentos de contratação da Administração Pública com as entidades do Terceiro Setor, instituídos pela Lei Federal n. 13.019/2014, buscando compreender em que medida o novo regime legal permite o cumprimento do Princípio Constitucional da Eficiência.

Palavras-chave: Administração Pública Consensual. Terceiro Setor. Administração Pública. MROSC. Princípio da Eficiência.

\begin{abstract}
:
This paper aims to discuss the new forms of contract between Public Administration and Third Sector entities, created by Federal Law No. 13.019/2014, in order to investigate whether the new legal regime allows the compliance with the Constitutional Principle of Efficiency.
\end{abstract}

Keywords: Consensual Public Administration. Third Sector. Public Administration. MROSC. Principle of Efficiency.

\section{Introdução}

De acordo com Floriano Peixoto de Azevedo Marques Neto, a emergência de novos processos políticos, sociais e econômicos na atualidade, que são marcados pela transnacionalização de processos decisórios e pelo surgimento de novos atores sociais (como as organizações internacionais, os grandes grupos e conglomerados econômicos, os movimentos sociais, etc.), fazem com que o papel central dos Estados Nacionais no processo de decisão política seja constantemente desafiado. (MARQUES NETO, 2002, p. 103). O espaço decisório a respeito das ações políticas do Estado passa, então, a ser compartilhado com os novos atores que emergem no tecido social, de modo que a atuação estatal, normalmente caracterizada pela unilateralidade, assume uma nova feição, em que o Estado assume o papel de mediação entre os vários interesses existentes na sociedade.

Neste novo panorama de complexificação e diversidade das demandas, interesses e atores sociais envolvidos na atuação administrativa, surgem as "organizações não governamentais", integrantes do chamado Terceiro Setor. Essas organizações,

\footnotetext{
* Bacharela em Direito pela Faculdade de Direito da Universidade de São Paulo. 
formadas a partir de grupos de interesse específicos, passam a desenvolver atividades de interesse social que anteriormente eram desenvolvidas pelo Estado ou que nunca foram por ele assumidas - o que também desafia o papel central da atuação estatal na promoção de interesses públicos. (MARQUES NETO, 2002, p. 122-123). O Estado, então, passa a conceber instrumentos por meio dos quais irá se relacionar com essas entidades não governamentais sem fins lucrativos para que, com elas, sejam promovidas atividades e políticas públicas de forma eficiente. Tem-se, assim, a origem do fenômeno de contratação pública com o Terceiro Setor para a realização e promoção de atividades de interesse público, conforme será mais bem tratado nos próximos tópicos deste artigo.

\section{As Políticas Públicas e Contratações com o Terceiro Setor}

As políticas públicas são conceituadas por Maria Paula Dallari Bucci (1997, p. 91) como "a coordenação dos meios à disposição do Estado, harmonizando as atividades estatais e privadas para a realização de objetivos socialmente relevantes e politicamente determinados". ${ }^{1}$ De fato, a emergência dos direitos fundamentais de segunda geração, caracterizados notadamente pela necessidade de prestações positivas dos Estados em relação aos seus cidadãos, fez com que as políticas públicas se tornassem um instrumento essencial para o oferecimento de direitos sociais, tais como saúde, educação, cultura, esporte, entre outros, à população.

Com o passar do tempo, a discussão a respeito das políticas públicas tem ganhado espaço no campo jurídico e despertado o interesse de seus estudiosos. Carlos Ari Sunfeld e André Rosilho ensinam que a noção de política pública acrescenta uma nova perspectiva e forma de compreensão do fenômeno jurídico, por meio da qual os institutos normalmente mobilizados pelo operador do Direito (tais como normas, regras de interpretação, competências, sanções, validade entre outros) serão inseridos e analisados dentro do campo mais amplo da ação administrativa ou governamental. (SUNDFELD; ROSILHO, 2014, p. 46).

O Direito, portanto, apresenta-se como importante instrumento para o funcionamento e estruturação de políticas públicas e, dentro do fenômeno da Administração Pública Consensual, a utilização mais frequente de instrumentos jurídicos de natureza contratual para a implementação de políticas governamentais é algo que reafirma a complementariedade entre as áreas do Direito e Políticas Públicas, bem como a importância da participação social de atores não estatais na sua execução.

Segundo a autora, as políticas públicas vão além da prestação de serviços públicos, abarcando igualmente as funções estatais de coordenação e fiscalização dos agentes públicos e privados. (BUCCI, 1997, p. 90). 
Nesse sentido, o Terceiro Setor, composto por entidades privadas sem fins lucrativos, apresenta-se como um dos possíveis parceiros do Poder Público para a execução de políticas públicas voltadas à população. As organizações do Terceiro Setor, por sua capilaridade e experiências acumulados ao longo do tempo, são capazes de oferecer soluções inovadoras e criativas para a promoção dos direitos sociais complexos e execução de atividades de interesse público de forma mais efetiva e eficiente. ${ }^{2}$

A este respeito, Laís Figueirêdo Lopes entende que os arranjos institucionais devem viabilizar a atuação colaborativa entre Administração Pública e sociedade civil, de forma a possibilitar o maior alcance, diversidade e porosidade das políticas públicas destinadas à solução dos complexos problemas existentes na sociedade, especialmente com relação às populações mais vulneráveis. A autora defende que a abertura de espaços de participação social dentro da Administração Pública mostra-se fundamental para a formulação, monitoramento, execução e fiscalização de políticas públicas. (LOPES; SOUZA; SANT'ANA; HERNANDEZ; ARAUJO JÚNIOR; SOUZA; MACEDO, p. 4). E continua, ressaltando a importância dos arranjos contratuais para a maior participação social no âmbito de execução de políticas públicas, in verbis:

\begin{abstract}
Além dos diferentes espaços de participação existentes, há na relação de vínculo contratual entre o Estado e as OSCs também uma forma de participação social. Cada vez que uma organização recebe recursos públicos para operar determinado projeto de interesse público pactuado com o governo - seja para fomento de projeto ou colaboração para a execução de política pública - ela também participa dos diferentes estágios do ciclo das políticas públicas.
\end{abstract}

A parceria permite uma série de ganhos institucionais. De um lado, o Estado ganha capilaridade, fica mais "poroso" em sua atuação com a execução de projetos por organizações da sociedade civil que são estratégicos para a implementação de políticas, programas ou ações governamentais. Por outro, as organizações participam da esfera pública de forma não estatal e ganham escala para amplificar o alcance de sua atuação de finalidade pública. Trata-se, pois, de complementaridade entre entes. (PEREIRA, 1997, p. 5, grifo nosso).

\footnotetext{
2 A Reforma do Estado, proposta por Bresser Pereira nos anos 1990, tinha como um de seus pilares o chamado processo de "publicização", por meio do qual uma das medidas previstas era o repasse dos serviços sociais às Organizações Sociais a partir da celebração de contrato de gestão com o Poder Público. Trata-se de espécie de contrato com entidades do Terceiro Setor, que acabou sendo concretizado com a edição da Lei $n$. 9.637/1998, e que consubstancia a tendência moderna de contratualização no âmbito das políticas públicas. (PEREIRA, 1997, p. 28-29).
} 
Por conseguinte, não há dúvidas acerca da importância da contratação pública com o Terceiro Setor como forma de implementação de políticas públicas, sendo um dos novos instrumentos que podem ser utilizados pelo Poder Público para o cumprimento de seus deveres constitucionais e que ganham centralidade dentro da perspectiva da Administração Pública Consensual.

Nesse ponto, é importante ressaltar que as contratações com o Terceiro Setor podem ser enquadradas dentro da atividade estatal mais ampla do fomento. $\mathrm{O}$ fomento estatal é caracterizado por atuações do Estado que objetivam incentivar (seja por indução ou por coerção) as ações e atividades desenvolvidas por atores privados, que busquem ou não finalidades lucrativas (setor empresarial e Terceiro Setor, respectivamente), de modo que pode ser entendido como um instrumento de intervenção estatal indireto, o qual pretende estimular os particulares a executarem atividades econômicas cuja execução gera benefícios sociais ou desestimular atividades que gerem prejuízos à sociedade. (MARQUES NETO, 2015, p. 407-408).

Isto posto, conclui-se que a formação de parcerias com as entidades do Terceiro Setor destinadas à execução de atividades de interesse público, mediante a transferência de recursos e bens públicos à entidade privada sem fins lucrativos, pode ser considerada uma forma de fomento estatal. Isso porque o Estado está, ao firmar tais parcerias, estimulando por meio da transferência de recursos e bens que as organizações sem fins lucrativos exerçam atividades privadas que geram benefícios para a sociedade, $o$ que está em consonância com o conceito de fomento.

Dentro dessa lógica, a Lei n. 13.019/2014, conhecida como Marco Regulatório das Organizações da Sociedade Civil (MROSC), apresenta-se como um instrumento a serviço do fomento às atividades privadas de interesse público. A nova legislação, no bojo do que já era feito pela Lei das Organizações Sociais (Lei n. 9.637/1998) e pela Lei das Organizações da Sociedade Civil de Interesse Público (Lei n. 9.790/1999), traz novos instrumentos de parceria entre a Administração Pública e as entidades do Terceiro Setor para a execução de atividades privadas de interesse público pelos particulares com o apoio do ente estatal.

\section{O Novo Marco Regulatório das Organizações da Sociedade Civil}

O conceito de Terceiro Setor é originário das ciências econômicas e sociais, tendo sido apropriada pelos estudiosos do Direito para denotar o grupo de entidades que não pertencem nem ao Primeiro Setor (Estado) nem ao Segundo Setor (Mercado), mas que reúnem ao mesmo tempo características de ambos os setores. São entidades privadas que, apesar de não integrarem a Administração Pública, se dedicam à prestação de atividades de interesse público sem intenção de lucro. (MARTINS, 2017, p. 264). 
Gustavo Justino de Oliveira (2008, p. 279) traz o conceito segundo o qual o Terceiro Setor é "o conjunto de atividades voluntárias desenvolvidas por organizações privadas não-governamentais e sem ânimo de lucro (associações e fundações), realizadas em prol da sociedade, independentemente dos demais setores (Estado e mercado), embora com eles possam firmar parcerias e receber investimentos (públicos e privados)".

Tomando como base tais noções de Terceiro Setor, o MROSC estabeleceu o conceito de Organização da Sociedade Civil, que seriam as entidades sujeitas ao regime da Lei n. 13.019/2014. De acordo com o seu art. 2ª , as Organizações da Sociedade Civil compreendem: (a) as entidades privadas sem fins lucrativos, que não distribuem valores aos seus associados, conselheiros, diretores, empregados, doadores ou terceiros, (b) as sociedades cooperativas previstas na Lei n. 9.867/1999 e (c) as organizações religiosas que se dedicam a atividades ou projetos de interesse público e de cunho social distintas daquelas de natureza exclusivamente religiosa. ${ }^{3}$

No âmbito do regime instituído pelo MROSC, são previstos três instrumentos de parceria que podem ser firmados entre Poder Público e Organizações da Sociedade Civil: (i) termo de colaboração, (ii) termo de fomento e (iii) acordo de cooperação.

De acordo com o art. $2^{\circ}$, VII, da Lei n. 13.019/2014, o termo de colaboração consiste no instrumento por meio do qual são celebradas as parcerias entre Administração Pública e Organização da Sociedade Civil para a consecução de finalidades de interesse público e recíproco, propostas pela Administração Pública e que envolvam a transferência de recursos financeiros.

Já os termos de fomento são definidos pelo art. $2^{\circ}$, VIII, da Lei n. 13.019/2014, como os instrumentos por meio dos quais são formalizadas as parcerias ente Administração Pública e Organização da Sociedade Civil para a realização de finalidades de interesse público e recíproco, propostas pela Organização da Sociedade Civil e que envolvem a transferência de recursos financeiros.

Como é possível notar, os conceitos de termo de colaboração e de termo de fomento são extremamente semelhantes, sendo que a diferença entre eles decorre da identificação de quem é responsável pela propositura da parceria. No caso do termo de colaboração, a proposta da parceria é feita pela Administração Pública, ao passo que tal papel cabe à Organização da Sociedade Civil no caso do termo de fomento.

O MROSC inova em relação às legislações dos anos 1990 no que se refere às espécies de entidades sem fins lucrativos que podem celebrar parcerias com a Administração, visto que dispensa a necessidade de um título jurídico específico para que a entidade do Terceiro Setor possa celebrar instrumentos de parceria com o Poder Público. A Lei das OSs (art. $1^{\circ}$ ) e a Lei das OSCIPs (art. $1^{\circ}$ ), por exemplo, trazem a necessidade de qualificações especiais como "Organização Social" ou "Organização da Sociedade Civil de Interesse Público", respectivamente, que são outorgadas pelo Ministério da Justiça mediante o preenchimento dos requisitos previstos nos respectivos diplomas legais. 
Por sua vez, os acordos de cooperação são definidos pelo art. $2^{\circ}$, VIII-A, da Lei n. 13.019/2014, como o instrumento por meio do qual são formalizadas as parcerias entre Administração Pública e Organização da Sociedade Civil para a consecução de finalidades de interesse público e recíproco que não envolvem a transferência de recursos financeiros. De acordo com o art. $5^{\circ}, \S 1^{\mathrm{o}}$, do Decreto n. 8.726/2016, ${ }^{4}$ a iniciativa da proposta do acordo de cooperação pode caber tanto à Administração quanto à Organização da Sociedade Civil.

Apesar de ser um instrumento de parceria que não envolve a transferência de recursos financeiros públicos, o acordo de cooperação pode compreender a transferência de recursos que não tenham natureza financeira como a doação ou comodato de bens públicos (art. $6^{\circ}$ do Decreto n. 8.726/2016).

Portanto, percebe-se que a identificação da espécie de parceria a ser celebrada entre a Administração e a Organização da Sociedade Civil decorre de uma dupla análise. Em primeiro lugar, deve-se investigar se existe a transferência de recursos financeiros ao parceiro privado. Caso não haja o repasse de recursos financeiros ou a parceria envolva somente a transferência de bens públicos ou outras formas de compartilhamento patrimonial, será o caso de celebração de um acordo de cooperação. Se, por outro lado, a parceria envolver a transferência de recursos financeiros, passa-se à análise da iniciativa da proposta da parceria: se realizada pela Administração Pública, o termo de colaboração é o instrumento que deverá ser firmado, ao passo que, se a iniciativa da parceria tiver sido realizada pela Organização da Sociedade Civil, ter-se-á hipótese de celebração de termo de fomento.

Nesse ponto, cabe indagar se a Lei n. 13.019/2014 dispõe sobre alguma vedação a respeito do objeto das parcerias a serem firmadas com as Organizações da Sociedade Civil. De acordo com seu art. 40, não podem ser celebradas parcerias com as Organizações da Sociedade Civil que tenham, por objeto, a delegação direta ou indireta das funções estatais de regulação, de fiscalização, de exercício do poder de polícia ou de quaisquer outras atividades exclusivas do Estado. A intenção do legislador, ao instituir tal vedação ao objeto do contrato, provavelmente foi a de evitar que as parcerias com o Terceiro Setor fossem utilizadas como forma de o Poder Público se desincumbir de suas funções exclusivas, delegando-as indevidamente a atores privados.

A este respeito, Cristiana Fortini, Luana Magalhães de Araújo Cunha e Priscila Gianetti Campos Pires entendem que a vedação do art. 40 seria uma forma de

$4 \quad$ Art. $5^{\circ}$. O acordo de cooperação é instrumento por meio do qual são formalizadas as parcerias entre a administração pública federal e as organizações da sociedade civil para a consecução de finalidades de interesse público e recíproco que não envolvam a transferência de recursos financeiros. $\S 1^{\circ}$. $O$ acordo de cooperação poderá ser proposto pela administração pública federal ou pela organização da sociedade civil. (BRASIL, 2016). 
assegurar que o fomento estatal esteja restrito às atividades privadas de caráter suplementar à atuação da Administração Pública e de evitar que haja a burla ao regime de direito público, que é próprio das atividades exclusivas do Estado, como se vê no seguinte trecho:

\begin{abstract}
A vedação à celebração de parcerias visando à celebração de atividades exclusivas do Estado expressa a preocupação do legislador de que os ajustes tenham, de fato, consecução de fim social, e não de atividades que deveriam atrair o regime contratual administrativo, mas que, em razão do regime mais flexível, tentam enquadrar-se como parcerias. Além disso, pressupõe-se estar no âmbito da atividade de fomento, sendo, portanto, atividade em caráter suplementar, sob risco de se ter uma formalização de parceria à substituição de verdadeiro contrato de prestação de serviços. (FORTINI; CUNHA; PIRES, 2017, p. 79).
\end{abstract}

Tendo em vista de tais considerações, pode-se afirmar que as parcerias com as Organizações da Sociedade Civil, tal como previstas pela Lei n. 13.019/2014, devem ser tidas como instrumento de fomento cujo objeto está limitado às atividades privadas de interesse público, não devendo ser utilizadas como forma de delegação de atividades que devem ser exclusivamente desenvolvidas pela Administração Pública. O emprego desses instrumentos contratuais deve ser realizado principalmente quando os parceiros privados se mostrem mais eficientes que o Poder Público na execução das atividades de interesse público.

Não seria lógico celebrar uma parceria com o Terceiro Setor se este não for mais eficiente do que a própria Administração na execução do objeto, o instrumento de parceria busca justamente as inovações e conhecimentos específicos detidos pelo setor privado sem fins lucrativos que possam gerar maior aproveitamento de recursos e oferecimento de maior quantidade de benefícios sociais à população atingida, razão pela qual o princípio da eficiência deve ser o guia do gestor público para a celebração e execução de tais parcerias.

\title{
4. O Princípio da Eficiência e a Lei Federal n. 13.019/2014
}

O princípio da eficiência foi introduzido na Constituição Federal de 1988 por meio da Emenda Constitucional n. 19, de 1998, a qual o alçou como um dos princípios que regem a atuação da Administração Pública brasileira, in verbis:

Art. 37. A administração pública direta e indireta de qualquer dos Poderes da União, dos Estados, do Distrito Federal e dos Municípios obedecerá aos princípios de legalidade, impessoalidade, moralidade, publicidade e eficiência e, também, ao seguinte: (Redação dada pela Emenda Constitucional n. 19, de 1998). (grifo nosso). 
O conceito de eficiência, tal como estudado pelas ciências econômicas e da administração, consiste na capacidade de se produzir o máximo de resultados com o mínimo de recursos disponíveis. No entanto, conforme defende Guilherme Adolfo dos Santos Mendes (2012, p. 362 e 373), o conceito meramente econômico de eficiência não é suficiente para atender aos propósitos perseguidos pelo Direito, a busca pela eficiência deve fazer com que o Estado adote ações que promovam maior número de direitos a seus cidadãos com a menor imposição de gravames ou restrições a suas liberdades. Assim, o autor entende que a execução de qualquer competência pelo Estado que tenha baixos custos, mas que, por outro lado, imponha sacrifícios consideráveis à população falha em seu propósito de atender ao princípio da eficiência.

Maria Sylvia Zanella Di Pietro (2017a, p. 154), de outra banda, afirma que o princípio da eficiência compreende dois aspectos distintos. O primeiro deles diz respeito ao "modo de atuação do agente público", de forma que será exigido dos administradores e gestores públicos o melhor desempenho de suas atribuições a fim de que, ao final, sejam alcançados melhores resultados. O segundo aspecto refere-se ao "modo de organizar, estruturar, disciplinar a Administração Pública", o que, para a autora, também possibilitaria o atingimento de melhores resultados na prestação de serviços públicos - ou, de forma mais abrangente, o princípio da eficiência direciona o desempenho de quaisquer funções pela Administração Pública com vistas ao atingimento de melhores resultados aos seus administrados.

Alexandre Santos de Aragão (2012, p. 375) destaca que o Direito Público contemporâneo precisa atender certas necessidades da sociedade e deve fazêlo eficientemente. O Poder Público deve buscar a realização da maior quantidade de finalidades de interesse público com a menor imposição de ônus possível, seja com relação ao próprio Estado, seja com relação aos direitos e liberdades de seus cidadãos.

Logo, nota-se que o princípio da eficiência é instrumental à atuação administrativa, servindo como parâmetro pelo qual o administrador público, ao implementar determinada política ou estruturar determinada ação, deve vislumbrar os bônus e ônus que serão gerados para a população em geral. E a Lei n. 13.019/2014 não foi indiferente a isto, tendo previsto o princípio da eficiência como um de seus fundamentos, como se vê no caput do art. $5^{\circ}$ :

Art. $5^{\circ}$. O regime jurídico de que trata esta Lei tem como fundamentos a gestão pública democrática, a participação social, o fortalecimento da sociedade civil, a transparência na aplicação dos recursos públicos, os princípios da legalidade, da legitimidade, da impessoalidade, da moralidade, da publicidade, da economicidade, da eficiência e da eficácia, destinando-se a assegurar: (Redação dada pela Lei n. 13.204, de 2015). 
I - o reconhecimento da participação social como direito do cidadão;

II - a solidariedade, a cooperação e o respeito à diversidade para a construção de valores de cidadania e de inclusão social e produtiva;

III - a promoção do desenvolvimento local, regional e nacional, inclusivo e sustentável;

IV - o direito à informação, à transparência e ao controle social das ações públicas;

$\mathrm{V}$ - a integração e a transversalidade dos procedimentos, mecanismos e instâncias de participação social;

VI - a valorização da diversidade cultural e da educação para a cidadania ativa;

VII - a promoção e a defesa dos direitos humanos;

VIII - a preservação, a conservação e a proteção dos recursos hídricos e do meio ambiente;

IX - a valorização dos direitos dos povos indígenas e das comunidades tradicionais;

$\mathrm{X}$ - a preservação e a valorização do patrimônio cultural brasileiro, em suas dimensões material e imaterial.

Observa-se que a Lei n. 13.019/2014 reconhece a instrumentalidade do princípio da eficiência para assegurar os objetivos listados nos incisos do caput do art. $5^{\circ}$ como essenciais ao novo regime jurídico do MROSC. E, além da previsão expressa do princípio da eficiência, há outras que trazem, de forma implícita, a influência deste princípio no novo regime de parcerias entre Administração Pública e entidades do Terceiro Setor. A título de exemplo, é possível indicar a previsão contida no art. $6^{\circ}$, I, da Lei n. 13.019/2014, em que a priorização do controle de resultados é mencionada como uma das diretrizes fundamentais do regime jurídico das parcerias regidas pelo MROSC.

O controle de resultados, conforme informa Dora Maria de Oliveira Ramos (2006, p. 47), é um dos mecanismos que foram utilizados no âmbito da reforma do Estado do século XX para a busca da Administração gerencial. A autora afirma que o realce dado ao princípio da eficiência durante esse período serviu como pedra de toque para o processo de substituição da "Administração burocrática", em que predomina o controle de meios, para uma "Administração gerencial", que se pauta predominantemente pelo controle de resultados.

Destarte, nota-se que o regime jurídico das parcerias das Organizações da Sociedade Civil e Administração Pública é informado pelo princípio da eficiência e por meio dele deve ser estudado. No próximo tópico, serão analisados os mecanismos da Lei n. 13.019/2014 que visam ao cumprimento do referido princípio constitucional da Administração Pública. 
5. Os mecanismos da Lei n. 13.019/2014 para o atendimento ao princípio da eficiência

A formalização e execução das parcerias entre Organizações da Sociedade Civil e Administração Pública podem ser divididas em quatro fases distintas: (i) fase de planejamento: na qual o Poder Público realizará estudos e levantamento de dados e avaliará a possibilidade de desencadear um procedimento de seleção de Organizações da Sociedade Civil para a celebração de termo de fomento, termo de colaboração ou acordo de cooperação, (ii) fase de seleção: em que serão escolhidas as Organizações da Sociedade Civil com as quais o Poder Público firmará instrumentos contratuais, (iii)fase de execução: na qual, uma vez escolhida a entidade, o objeto da parceria será propriamente executado pelas partes e (iv) fase de prestação de contas: na qual a Organização da Sociedade Civil demonstrará que foi capaz de cumprir com o objeto contratual nos termos em que foi celebrado, o que será feito por meio do procedimento de prestação de contas.

Em todas as fases da parceria supramencionadas, a Lei n. 13.019/2014 previu que instrumentos e mecanismos que possibilitam sua execução mais eficiente, dentre os quais merecem destaque o Procedimento de Manifestação de Interesse Social (PMIS), o Chamamento Público e o Procedimento de Prestação de Contas.

a) Fase de Planejamento

A Fase de Planejamento (ou de Pré-Seleção) compreende o momento que antecede a decisão da Administração Pública em buscar parceiros privados para celebrar os instrumentos de parceria, em que é feita a avaliação a respeito da possibilidade e conveniência de ser aberto o procedimento de seleção dos parceiros privados para celebração do instrumento contratual.

A este respeito, Bruno Belem afirma o seguinte:

A formalização de qualquer modelo de parceria entre o Poder Público e o setor privado, tenha este finalidade lucrativa ou não, necessariamente envolverá algum tipo de estudo e demandará prévio planejamento. Não se pode admitir que a Administração Pública celebre negócios jurídicos, por vezes assumindo elevados custos financeiros, sem antes identificar a necessidade que se pretende suprir, a viabilidade do tipo de relação jurídica que se quer estabelecer e, em especial, a melhor forma de se aplicar os recursos públicos direcionados à implementação da ação desejada.

Os atos preparatórios acima mencionados são necessários para a realização do princípio da eficiência na Administração Pública, pois, a partir deles, o gestor público poderá identificar a melhor relação custo-benefício 
das ações administrativas a serem adotadas. (BELEM, 2017, p. 208, grifo nosso).

A lição do autor é irretocável. O planejamento das políticas públicas pelo Estado é etapa essencial para que sejam identificadas as necessidades que se pretende satisfazer por meio das ações governamentais. Nesta etapa, a realização de estudos e mapeamentos pelo Poder Público permite que seja avaliada a viabilidade econômica, técnica e jurídica da ação do ente público e sua capacidade de atender às finalidades a que se destina determinada política pública (juízo de adequação entre os meios adotados e as finalidades que se pretende alcançar). Além disso, os estudos e mapeamentos preliminares permitem que a Administração Pública possa decidir qual a melhor abordagem da ação administrativa, isto é, se o Estado deve tomar para si a execução da política pública ou, se por outro lado, deve buscar a celebração de parcerias com o setor privado, seja ele com ou sem fins lucrativos.

Tendo em vista a importância desta fase preliminar de planejamento, o Poder Público pode optar por realizar ele mesmo os estudos e levantamentos necessários para que certa política pública seja implementada ou contar com o auxílio da iniciativa privada. O Procedimento de Manifestação de Interesse Social (PMIS), nesse sentido, é a ferramenta, prevista pela Lei n. 13.019/2014, para que a fase de planejamento da parceria seja compartilhada com a sociedade, possibilitando a estruturação participativa de políticas públicas. Conforme define o art. 18 do MROSC, o PMIS é o "instrumento por meio do qual as organizações da sociedade civil, movimentos sociais e cidadãos poderão apresentar propostas ao poder público para que este avalie a possibilidade de realização de um chamamento público objetivando a celebração de parceria”.

O PMIS, portanto, é procedimento que visa aproximar a sociedade civil da estruturação de políticas públicas, permitindo que o Poder Público possa ter acesso a modelos inovadores de atuação que foram desenvolvidos pelas Organizações da Sociedade Civil, por movimentos sociais ou cidadãos, a partir dos conhecimentos técnicos, financeiros e jurídicos que são detidos pela iniciativa privada e que, muitas vezes, não estão ao alcance do Poder Público. Conforme aponta Bruno Belem, dentre as vantagens trazidas pela adoção do PMIS, podem ser apontadas: (a) a maior agilidade na produção dos estudos destinados à formulação de políticas públicas, (b) o não comprometimento imediato de recursos financeiros na realização de tais estudos, visto que a iniciativa privada arcará com os custos necessários para realizar os levantamentos e mapeamentos necessários em um primeiro momento, (c) a possibilidade de se acessar modelos inovadores de prestação de atividades de interesse público e soluções tecnológicas, (d) economia na elaboração dos projetos, (e) possibilidade de avaliar, antes da realização de chamamento público, o interesse da iniciativa privada em desenvolver tais projetos voltados a atividades de interesse público, e (f) abrir espaço para a participação da sociedade civil na definição do 
objeto e escopo das parcerias com Organizações da Sociedade Civil. (BELEM, 2017, p. $217) .^{5}$

Nesse ponto, cabe ressaltar que a realização do PMIS pela Administração Pública não implica necessariamente na abertura de chamamento público para a seleção de Organização da Sociedade Civil, o que dependerá do interesse do Poder Público em continuar com o projeto para celebração de parcerias com entidades privadas sem fins lucrativos. ${ }^{6}$ Tampouco a realização do PMIS dispensa a convocação do chamamento público para a seleção do parceiro que executará o projeto ou atividade sugerido na proposta, isto é, não é porque o Poder Público manifestou interesse em continuar com proposta apresentada, que seu propositor será necessariamente o executor da parceria. O procedimento de chamamento público terá que ser necessariamente aberto para que todos os interessados em realizar o objeto da parceria possam participar do processo competitivo.

b) Fase de seleção

Durante longo tempo, a doutrina administrativista debruçou-se sobre a questão da obrigatoriedade de licitação para contratar com as entidades do Terceiro Setor, pontuando para a tendência de "fuga" do regime da Lei n. 8.666/1993. A este respeito, Carlos Ari Sunfeld e Rodrigo Pagani de Souza afirmam o seguinte:

Importa perceber, inclusive, que a moderna parceria cuja essência é a de um contrato vai, paulatinamente, em sintonia com esta sua própria natureza, se deixando chamar por contrato (p.ex., "contrato de gestão", "contrato de repasse", "contrato de direito público" ou "contratação"). Quando isto não sucede e ela continua a atender, a despeito da sua essência, pelos apelidos de antigamente - "acordo", "termo", "ajuste" ou qualquer outro que fuja à chapa contratual - o apelido de fuga explica-se por uma de suas alternativas: 1) a inércia da tradição no uso de expressões correntes no tráfico jurídico; ou 2) a necessidade gerencial de fuga do regime licitatório ditado pelo defasado Estatuto das Licitações e Contratos Administrativos Brasileiro (Lei n. 8.666/93). (SUNDFELD; SOUZA, 2011, p. 58, grifo nosso).

\footnotetext{
5 É importante pontuar que Bruno Belem (2017, p. 218) procura demonstrar também os riscos que estão envolvidos no Procedimento de Manifestação de Interesse Social (PMIS). Segundo o autor, os principais riscos que podem ser apontados acerca do PMIS dizem respeito: (a) à possibilidade de captura do parceiro público pelo privado, (b) a inefetividade do procedimento por falta de capacidade técnica e operacional dos agentes públicos para avaliar a qualidade da proposta, (c) o conflito de interesses e eventual prejuízo à competitividade do procedimento de chamamento público que será realizado após o PMIS, (d) fomento à cultura da desconfiança.

6 Cf. Art. 21, caput, da Lei n. 13.019/2014.
} 
A Lei n. 13.019/2014, procurando estancar tal polêmica com relação às parcerias celebradas dentro de seu regime, expressamente determinou que a Lei Geral de Licitações e Contratos Administrativos (Lei n. 8.666/1993) não é aplicável aos termos de colaboração, termos de fomento e acordos de cooperação, ${ }^{7}$ assim como também limitou a aplicabilidade do convênio administrativo aos (i) convênios de direito público, isto é, celebrados entre entes federados ou por entidades componentes da Administração Pública, e (ii) aos convênios celebrados com entidades filantrópicas e sem fins lucrativos nos termos do $\S 1^{\circ}$ do art. 199 da Constituição Federal.

Apesar de a aplicação da Lei n. 8.666/1993 ter sido afastada das parcerias com as Organizações da Sociedade Civil, pode-se dizer que a Lei n. 13.019/2014 trouxe para dentro de seu regime alguns institutos previstos naquela lei, como é o caso do chamamento público que se assemelha enormemente a um procedimento de licitação. De acordo com o art. $2^{\circ}$, XII, da Lei n. 13.019/2014, o chamamento público é “o procedimento destinado a selecionar organização da sociedade civil para firmar parceria por meio de termo de colaboração ou de fomento, no qual se garanta a observância dos princípios da isonomia, da legalidade, da impessoalidade, da moralidade, da igualdade, da publicidade, da probidade administrativa, da vinculação ao instrumento convocatório, do julgamento objetivo e dos que lhes são correlatos".

Dessa forma, percebe-se que o chamamento público é procedimento que busca trazer, para o regime das parcerias com as Organizações da Sociedade Civil, os princípios constitucionais da Administração Pública, previstos no caput do art. 37 da Constituição Federal, dentre os quais ressaltamos o princípio da eficiência. Nesse ponto, concordamos com a consideração realizada por Rafael Arruda Oliveira sobre o chamamento público, em que afirma:

(...) a Lei Federal n. 13.019/14, semelhantemente ao que faz a Lei n. 8.666/93, projeta, no plano infraconstitucional, aqueles princípios jurídico-constitucionais estampados no art. 37, caput, da Constituição Federal, para o específico efeito de que, no bojo de um processo seletivo conduzido de forma pública, impessoal e baseada em critérios objetivos, tal qual um procedimento licitatório, à semelhança de procura assegurar a igualdade de tratamento aos participantes, a publicidade de todos os trâmites e a motivação das decisões administrativas seja escolhida a entidade privada sem fins econômicos que melhor atenda às exigências da Administração. (OLIVEIRA, 2017, p. 308, grifo do autor).

Cf. Art. 84 da Lei n. 13.019/2014. 
Portanto, o chamamento público pode ser considerado um mecanismo a serviço do princípio da eficiência justamente por possibilitar a escolha da entidade sem fins lucrativos que tenha capacidade e meios para atender às exigências e finalidades visadas pela Administração Pública, o que é feito por meio de um processo competitivo entre todos os interessados.

Além do chamamento público, outro instrumento que se mostra importante para o atendimento ao princípio da eficiência na fase de seleção das Organizações da Sociedade Civil consiste no Plano de Trabalho. O MROSC condiciona a celebração do termo de colaboração e do termo de fomento à aprovação do Plano de Trabalho apresentado pela Organização da Sociedade Civil. ${ }^{8}$

De acordo com o art. 22 da Lei n. 13.019/2014, o Plano de Trabalho deve conter: (a) a descrição da realidade que será objeto da parceria, devendo ser demonstrada a conexão entre essa realidade e as atividades ou projetos e metas a serem atingidas, (b) a descrição das metas a serem atingidas e de atividades ou projetos a serem executados, (c) a previsão de receitas e despesas a serem realizadas durante a execução das atividades ou dos projetos previstos na parceria, (d) a forma de execução das atividades ou dos projetos e de cumprimento das metas a eles atreladas e (e) a definição dos parâmetros a serem usados para aferir o cumprimento das metas contidas no Plano de Trabalho.

Segundo Leandro Marins de Souza (2017, p. 371-372), o rigor na definição das metas e resultados que se pretende alcançar por meio da parceria é de extrema importância para fins de controle da parceria, visto que seu descumprimento gerará certas consequências à Organização da Sociedade Civil, como, por exemplo, a rejeição de sua prestação de contas. Ademais, caso a execução da parceria seja realizada em desconformidade com o Plano de Trabalho apresentado e aprovado pela Administração Pública, poderão ser aplicadas as sanções de (i) advertência, (ii) suspensão temporária da participação em chamamentos públicos ou impedimento temporário de firmar parcerias ou contratos com o Poder Público e (iii) declaração de inidoneidade para participar de chamamentos públicos ou celebrar parcerias ou contratos com órgãos governamentais. ${ }^{9}$

Portanto, o Plano de Trabalho pode ser considerado como o instrumento importante para o controle das parcerias firmadas entre Poder Público e entidades sem fins lucrativos dentro do regime estabelecido pela Lei n. 13.019/2014 e, portanto, atua a serviço da maior eficiência do contrato celebrado.

\footnotetext{
8 Art. 35. A celebração e a formalização do termo de colaboração e do termo de fomento dependerão da adoção das seguintes providências pela administração pública: (...) IV-aprovação do plano de trabalho, a ser apresentado nos termos desta Lei; (BRASIL, 2014, grifo nosso).

9 Cf. Art. 73 da Lei n. 13.019/2014.
} 
c) Fase de execução

Na fase de execução, o objeto da parceria será devidamente executado pela Organização da Sociedade Civil, de acordo com o Plano de Trabalho aprovado pela Administração Pública.

Para realizar as atividades e projetos para as quais foi selecionada, a Organização da Sociedade Civil precisará, muitas vezes, se valer de serviços e insumos fornecidos por terceiros contratados. Inicialmente a Lei n. 13.019/2014 previu uma seção inteira dedicada à regulação das contratações realizadas pelas Organizações da Sociedade Civil, na qual estava consignada a necessidade de um regulamento de compras e contratações para designar a forma pela qual a entidade privada sem fins lucrativas contrataria seus fornecedores e parceiros, o que foi integralmente revogado pela reforma promovida pela Lei n. 13.204/2015. Conforme aponta Maria Sylvia Zanella Di Pietro (2017, p. 378), as alterações promovidas pela Lei n. 13.204/2015 fizeram com que deixasse de existir qualquer forma de licitação para as contratações das Organizações da Sociedade Civil realizadas com terceiros, tendo sido eliminada inclusive a previsão de observância aos princípios da licitação, que estavam mencionados no art. 43 do MROSC..$^{10}$

A eliminação da necessidade de licitação para a contratação com terceiros é louvável, pois evita que a atuação da Organização da Sociedade Civil fique engessada pelo procedimento específico estabelecido no regulamento de compras e contratações, mas, por outro lado, deveria ter sido mantida a observância aos princípios que inicialmente estavam consignados no art. 43 (princípios da legalidade, da moralidade, da boa-fé, da probidade, da impessoalidade, da economicidade, da eficiência, da isonomia, da publicidade, da razoabilidade, de julgamento objetivo e a busca permanente por qualidade e durabilidade).

Ainda na fase de execução da parceria, a Administração Pública, consoante o art. 58 da Lei n. 13.019/2014, efetuará o monitoramento e a avaliação do cumprimento do objeto da parceria, podendo inclusive se utilizar de apoio técnico de terceiros para realizar tal incumbência ou delegá-la a órgãos ou entidades que tenham maior proximidade ao local

10 Art. 43. As contratações de bens e serviços pelas organizações da sociedade civil, feitas com o uso de recursos transferidos pela administração pública, deverão observar os princípios da legalidade, da moralidade, da boa-fé, da probidade, da impessoalidade, da economicidade, da eficiência, da isonomia, da publicidade, da razoabilidade e do julgamento objetivo e a busca permanente de qualidade e durabilidade, de acordo com o regulamento de compras e contratações aprovado para a consecução do objeto da parceria. (Revogado pela Lei n. 13.204, de 2015) $\S 1^{\circ}$. O processamento das compras e contratações poderá ser efetuado por meio de sistema eletrônico disponibilizado pela administração pública às organizações da sociedade civil, aberto ao público via internet, que permita aos interessados formular propostas. (Revogado pela Lei n. 13.204, de 2015) § $2^{\circ}$. O sistema eletrônico de que trata o $\S 1^{\circ}$ conterá ferramenta de notificação dos fornecedores do ramo da contratação que constem do cadastro de que trata o art. 34 da Lei n. 8.666, de 21 de junho de 1993. (Revogado pela Lei n. 13.204, de 2015). (BRASIL, 2014). 
em que estão sendo aplicados os recursos financeiros advindos da parceria. ${ }^{11}$ Além disso, está previsto que a Administração Pública, nas parcerias com prazo de duração superior a um ano, deve realizar pesquisas de satisfação com os beneficiários do serviço ou projeto a fim de utilizar os resultados da pesquisa como subsídios para avaliar a parceria firmada e o cumprimento de seus respectivos objetivos, bem como para eventual readequação e ajuste de metas e atividades inicialmente acordadas entre as partes.

Outrossim, o MROSC prevê que um relatório técnico de monitoramento e avaliação da parceria deve ser elaborado por parte da Administração Pública contratante nos seguintes termos:

Art. 59. A administração pública emitirá relatório técnico de monitoramento e avaliação de parceria celebrada mediante termo de colaboração ou termo de fomento e o submeterá à comissão de monitoramento e avaliação designada, que o homologará, independentemente da obrigatoriedade de apresentação da prestação de contas devida pela organização da sociedade civil. Redação dada pela Lei n. 13.204, de 2015).

$\S 1^{\circ} \mathrm{O}$ relatório técnico de monitoramento e avaliação da parceria, sem prejuízo de outros elementos, deverá conter: (Redação dada pela Lei n. 13.204, de 2015).

I - descrição sumária das atividades e metas estabelecidas;

II - análise das atividades realizadas, do cumprimento das metas e do impacto do beneficio social obtido em razão da execução do objeto até o periodo, com base nos indicadores estabelecidos e aprovados no plano de trabalho;

III - valores efetivamente transferidos pela administração pública; (Redação dada pela Lei n. 13.204, de 2015).

IV - (revogado); (Redação dada pela Lei n. 13.204, de 2015).

$\mathrm{V}$ - análise dos documentos comprobatórios das despesas apresentados pela organização da sociedade civil na prestação de contas, quando não for comprovado o alcance das metas e resultados estabelecidos no respectivo termo de colaboração ou de fomento; (Redação dada pela Lei n. 13.204, de 2015).

VI - análise de eventuais auditorias realizadas pelos controles interno e externo, no âmbito da fiscalização preventiva, bem como de suas conclusões e das medidas

$\overline{11 \quad \text { Cf. Art. 58, caput }}$ e $\S 1^{\circ}$, da Lei n. 13.019/2014. 
que tomaram em decorrência dessas auditorias. (Redação dada pela Lei n. 13.204, de 2015).

$\S 2^{\circ}$ No caso de parcerias financiadas com recursos de fundos específicos, o monitoramento e a avaliação serão realizados pelos respectivos conselhos gestores, respeitadas as exigências desta Lei. (Incluído pela Lei n. 13.204, de 2015). (grifo nosso).

Um dos objetivos do relatório técnico de monitoramento e avaliação, como é possível perceber pela leitura do art. $59, \S 1^{\circ}$, II, é demonstrar o cumprimento das metas e resultados definidos no Plano de Trabalho e, principalmente, o impacto social gerado por conta da execução do objeto da parceria. Tal relatório será um dos documentos a serem analisados pela Administração Pública na fase de prestação de contas, ${ }^{12}$ o que também faz dele um instrumento importante para aferir o cumprimento do princípio da eficiência nas parcerias com as Organizações da Sociedade Civil, visto que seu conteúdo procurará investigar e demonstrar que os resultados desejados pelo Poder Público com aquela parceria foram devidamente alcançados e os benefícios dela decorrentes puderam atingir os administrados para quem a política pública foi desenvolvida.

Por fim, no que se refere à fase de execução, cabe ressaltar a possibilidade de atuação em rede de duas ou mais Organizações da Sociedade Civil, que foi aberta pelo art. 35-A da Lei n. 13.019/2014. De acordo com o referido dispositivo, as Organizações da Sociedade Civil podem se associar para executar o objeto dos termos de fomento ou de colaboração, permanecendo a entidade signatária da parceria com integral responsabilidade sobre sua execução.

A previsão da atuação em rede das Organizações da Sociedade Civil também é reveladora da busca por maior eficiência na execução das parcerias com as entidades sem fins lucrativos. Isso porque a utilização de formas associativas de atuação permite que Organizações da Sociedade Civil que possuam expertise em áreas diferentes possam unir suas experiências e conhecimentos a fim de executar o objeto da parceria de forma mais adequada ao atendimento das metas e resultados contratualmente estabelecidos.

d) Fase de prestação de contas

Finalmente, a fase de prestação de contas inicia-se após finalizada a execução do objeto da parceria, devendo ser realizada em até 90 dias após o término da

12 Cf. Art. 66, parágrafo único, da Lei n. 13.019/2014. 
vigência da parceria ou ao final de cada exercício nos casos em que tiver duração superior a um ano. ${ }^{13}$

Conforme dispõe o art. 64 da Lei n. 13.019/2014, a prestação de contas deve trazer elementos que possibilitem o gestor da parceria ${ }^{14}$ avaliar o andamento da execução da parceria ou concluir que ela foi executada conforme o convencionado, com a descrição detalhada das atividades realizadas pelo parceiro e a comprovação de que as metas e resultados esperados foram atingidos até o período da prestação de contas.

Segundo Rodrigo Augusto Lazzari Lahoz (2017, p. 382), a prestação de contas é instrumento que objetiva realizar o controle e regulação das atividades que foram desenvolvidas com o uso de recursos financeiros que foram transferidos à Organização da Sociedade Civil. E, na lógica da Lei n. 13.019/2014, tal controle pretende avaliar especialmente se as atividades desenvolvidas no seio da parceria foram capazes de cumprir com as metas e resultados visados, o que é evidenciado pelo conteúdo dos documentos que serão analisados nesta fase.

Após a análise desses relatórios e documentos, o gestor da parceria deve emitir um parecer técnico de análise da prestação de contas, em que deve analisar a eficácia e efetividade das atividades promovidas pela Organização da Sociedade Civil, mencionando especialmente (a) os resultados já alcançados e seus benefícios, (b) os impactos econômicos e sociais gerados, (c) o grau de satisfação do público-alvo, (d) a possibilidade de sustentabilidade das ações a longo prazo e após a conclusão do objeto pactuado. ${ }^{15}$ Ao final da análise, a prestação de contas será julgada como (i) regular, (ii) regular com ressalvas ou (iii) irregular, conforme os parâmetros estabelecidos no art. 72 do MROSC.

6. Conclusão: Seriam as parcerias previstas pela Lei n. 13.019/2014 uma solução de eficiência para as políticas públicas no Brasil?

A preocupação com a eficiência das parcerias com o Terceiro Setor não nasce com a Lei n. 13.019/2014. No regime da Lei das OSs (Lei n. 9.637/1998) e da Lei das OSCIPs (Lei n. 9.790/1999), já era notada a preocupação do legislador infraconstitucional com a prestação eficiente das parcerias firmadas com as entidades privadas sem fins lucrativos e com a prevalência do controle de resultados. À vista disso,

\footnotetext{
13 Cf. Art. 69 da Lei n. 13.019/2014.

14 Art. $2^{\circ}$ Para os fins desta Lei, considera-se: VI - gestor: agente público responsável pela gestão de parceria celebrada por meio de termo de colaboração ou termo de fomento, designado por ato publicado em meio oficial de comunicação, com poderes de controle e fiscalização; (Redação dada pela Lei n. 13.204, de 2015). (BRASIL, 2014).

15 Cf. Art. 67, $\S 4^{\circ}$, da Lei n. 13.019/2014.
} 
cabe perguntar: o que a Lei n. 13.019/2014 traz de inovações em relação às leis anteriores para que possamos considerá-la mais efetiva no atingimento do princípio da eficiência nas parcerias com o Terceiro Setor? Seria ela uma solução?

A primeira diferença mais notável da Lei n. 13.019/2014 para a Lei das OSs e das OSCIPs diz respeito à desnecessidade de qualificação específica das entidades do Terceiro Setor que celebrarão parcerias com a Administração Pública. Como já tivemos a oportunidade de expor neste trabalho, o MROSC não exige nenhum título ou qualificação jurídico específico, tampouco elenca em quais áreas específicas a Organização da Sociedade Civil deve atuar, diferentemente do que ocorre na Lei das $\mathrm{OSs}^{16}$ e na Lei das OSCIPs. ${ }^{17} \mathrm{O}$ efeito prático disto é que o MROSC abre espaço para que mais entidades privadas sem fins lucrativos possam ter suas atividades fomentadas pelo Estado via celebração de termos de fomento, termos de colaboração ou acordos de cooperação e, portanto, haverá mais competidores interessados em disputar os chamamentos públicos convocados pela Administração Pública. Para fins de eficiência, maior competição entre os interesses permite que projetos mais arrojados e inovadores sejam objeto de análise e seleção por parte do Poder Público, algo que certamente está em consonância com o princípio da eficiência.

Outrossim, pode-se ressaltar a previsão do Procedimento de Manifestação de Interesse Social (PMIS), que não era previsto nas leis anteriores sobre parcerias com o Terceiro Setor. O legislador infraconstitucional foi inovador ao transpor o instituto do Procedimento de Manifestação de Interesse, já previsto na Lei n. 8.987/1995 ${ }^{18}$ que trata das concessões comuns e na Lei n. 11.079/2004 ${ }^{19}$ que dispõe sobre parcerias públicoprivadas (PPP), para o campo das parcerias com as Organizações da Sociedade Civil. Trata-se de instrumento que pode ser útil na implementação de medidas e ações inovadoras que, gestadas a partir dos conhecimentos e experiências detidos pela iniciativa privada, são apresentadas pelos particulares para implementação no setor público, sendo outra inovação trazida pelo MROSC em relação às legislações anteriores que se pauta pela busca de maior eficiência.

No âmbito do processo competitivo entre as entidades interessadas, outra inovação da Lei n. 13.019/2014 corresponde à previsão de um procedimento claro de chamamento público, que não era explicitamente previsto nas legislações anteriores. O MROSC traz maior segurança jurídica para as Organizações da Sociedade Civil ao estabelecer os procedimentos e critérios utilizados para seleção do parceiro que celebrará

\footnotetext{
16 Cf. Art. $1^{\circ}$ da Lei n. 9.637/1998.

17 Cf. Art. $3^{\circ}$ da Lei n. 9.790/1999.

18 Cf. Art. 21 da Lei n. 8.987/1995.

19 Cf. Art. $3^{\circ}$ da Lei n. 11.079/2004.
} 
os instrumentos de parceria previstos na Lei, algo que confere maior transparência a respeito da forma de seleção, mas também permite que o Poder Público, ao elaborar o instrumento de convocação do chamamento público, determine critérios que tencionem as Organizações da Sociedade Civil a elaborar propostas mais inovadoras e mais factíveis a, de fato, alcançar os resultados vislumbrados pelo Poder Público em determinada política pública. Ademais, o chamamento público permite que haja um maior controle jurídico e social sobre os procedimentos de seleção das entidades do Terceiro Setor que contratarão com a Administração.

Outra diferença que pode ser pontuada em relação ao regime do MROSC em comparação com as leis anteriores se relaciona com a necessidade ou não de um regulamento específico de contratação de bens e serviços por parte da entidade do Terceiro Setor. As Leis n. 9.637/1998 ${ }^{20}$ e n. 9.790/1999 $9^{21}$ trazem previsões que exigem que a Organização Social e a Organização da Sociedade Civil de Interesse Público, respectivamente, editem regulamentos específicos nos quais são previstos os procedimentos de aquisição de bens e contratação de serviços com terceiros. De certa forma, o regime das OSs e OSCIPs busca trazer ares publicísticos para dentro das parcerias com as entidades privadas do Terceiro Setor, fazendo com que o modo pelo qual se relacionam e contratam com terceiros esteja mais próximo dos métodos públicos do que dos métodos privados de gestão.

A Lei n. 13.019/2014, após a reforma promovida pela Lei n. 13.204/2015, deixou de prever a necessidade de regulamento para contratações de terceiros e procurou privilegiar os métodos privados de contratação, algo que inclusive é afirmado pelo seu Decreto regulamentador ${ }^{22}$ e que evita a morosidade dos métodos licitatórios da Administração Pública. Trata-se de opção feita pelo legislador que confere maior liberdade e dinamicidade às parcerias firmadas com as Organizações da Sociedade Civil, permitindo que estas celebrem arranjos contratuais com terceiros da forma que melhor atenda às suas necessidades e mediante uso de métodos mais inovadores, menos burocráticos e mais econômicos que estão à disposição da iniciativa privada.

Outrossim, outra inovação trazida pela Lei n. 13.019/2014 refere-se à previsão explícita de sanções administrativas que podem ser aplicadas nos casos em que a Organização da Sociedade Civil não cumprir com o Plano de Trabalho e metas nele estabelecidas. $\mathrm{O}$ art. 73 da referida Lei prevê, para os casos de execução da parceria em desacordo com o plano de trabalho e com as normas da Lei, as sanções de (i) advertência, (ii) suspensão temporária da participação em chamamento público e impedimento de

$20 \quad$ Cf. Art. 17 da Lei n. 9.637/1998.

21 Cf. Art. 14 da Lei n. 9.790/1999.

22 Art. 36. As compras e contratações de bens e serviços pela organização da sociedade civil com recursos transferidos pela administração pública federal adotarão métodos usualmente utilizados pelo setor privado. (...) (BRASIL, 2016, grifo nosso). 
celebrar parceria ou contrato com órgãos e entidades da esfera de governo da administração pública sancionadora, por prazo não superior a dois anos, e (iii) declaração de inidoneidade para participar de chamamento público ou celebrar parceria ou contrato com órgãos e entidades de todas as esferas de governo, enquanto perdurarem os motivos determinantes da punição ou até que seja promovida a reabilitação perante a própria autoridade que aplicou a penalidade, que será concedida sempre que a organização da sociedade civil ressarcir a administração pública pelos prejuízos resultantes e após decorrido o prazo da sanção aplicada com base no inciso II.

A Lei das $\mathrm{OSs}^{23} \mathrm{e}$ a Lei das $\mathrm{OSCIPs},{ }^{24}$ por sua vez, contêm disposições praticamente idênticas entre si sobre os casos de irregularidades ou ilegalidades na aplicação de recursos públicos. De acordo com as referidas leis, os responsáveis por fiscalizar a execução dos termos de parceria ou contratos de gestão, ao tomarem conhecimento de irregularidade ou ilegalidade na aplicação dos recursos de origem pública, devem dar ciência ao Tribunal de Contas competente e ao Ministério Público. Para além disso, ambas Leis dispõem que, a depender da gravidade dos fatos ou do interesse público, nos casos de malversação de bens ou recursos públicos, os responsáveis por fiscalizar a execução das parcerias devem apresentar representação ao Ministério Público, à AdvocaciaGeral da União ou à Procuradoria, para que estes requeiram em juízo a decretação da indisponibilidade dos bens da entidade e o sequestro dos bens de seus dirigentes, de agentes públicos ou quaisquer terceiros que possam ter se enriquecido ilicitamente ou causado prejuízo do Erário.

Portanto, percebe-se que a Lei n. 13.019/2014 vai um pouco além das Leis n. 9.637/1998 e n. 9.790/1999 e estabelece sanções para as Organizações da Sociedade Civil que não executarem devidamente o Plano de Trabalho. Trata-se de sanção que é aplicada diretamente pela Administração Pública, sem depender da atuação do Ministério Público, da Advocacia-Geral da União ou da Procuradoria, e que, de certa forma, atua como um mecanismo de pressão para que a Organização da Sociedade Civil execute cuidadosamente o Plano de Trabalho e alcance as metas e resultados nele propostos.

A despeito das inovações trazidas pelo MROSC, alguns autores entendem que a carga burocrática trazida pelas suas disposições pode impactar na eficiência da execução das parcerias com as Organizações da Sociedade Civil. A este respeito, Gustavo Justino de Oliveira e Carolina Filipini Ferreira afirmam que o viés da Lei n. 13.019/2014 voltado ao combate da corrupção fez com que fossem inseridas regras com alta carga

$\begin{array}{ll}23 & \text { Cf. Art. } 9^{\circ} \text { e } 10 \text { da Lei n. 9.637/1998. } \\ 24 & \text { Cf. Art. } 12 \text { e } 13 \text { da Lei n. 9.790/1999. }\end{array}$ 
burocrática e com rigoroso formalismo, algo que seria antagônico ao princípio da eficiência que deve nortear a celebração e execução dessas parcerias. ${ }^{25}$

No mesmo sentido, Rodrigo Pagani de Souza expressa igual preocupação com relação ao excesso burocrático trazido pela Lei n. 13.019/2014. Conforme afirmou em artigo sobre a Administração Pública de resultados, "embora com preocupante exagero - por ter pormenorizado excessivamente em lei obrigações gerais, para um espectro muito amplo de parcerias e organizações -, a Lei n. 13.019/2014 acentuou uma tendência anterior de exigência de controle focado nos resultados dessas parcerias com entidades do Terceiro Setor". (SOUZA R., 2017, p. 55, grifo nosso).

Denise Dora e Eduardo Pannunzio, em artigo que analisa o anteprojeto de Lei das Organizações Sociais, procuram pontuar os avanços e retrocessos do MROSC. Entre os pontos positivos do novo regime das entidades do Terceiro Setor, os autores ressaltam (a) a maior ênfase dada à etapa de planejamento, (b) a elevação dos níveis de transparência e participação, (c) a ampliação do acesso das entidades do Terceiro Setor às parcerias firmadas com a Administração Pública, principalmente por conta do estabelecimento do procedimento de chamamento público com critérios objetivos de seleção, (d) o maior respeito à autonomia das OSCs nas várias etapas do projeto, visto que há maior autonomia para que elas definam os meios que se valerão para executar o objeto da parceria, responsabilizando-se pelo cumprimento das metas pactuadas, e adicionalmente podemos pontuar a revogação da necessidade de um regulamento próprio para aquisição de bens e contratação de serviços, que ocorreu após a edição do artigo ora comentado, (e) a possibilidade de execução em rede do projeto, (f) a autorização para custeio de despesas institucionais e ( $\mathrm{g}$ ) simplificação e melhoria dos instrumentos de controle. (DORA; PANNUZIO, 2013, p. 14-21).

De outro lado, os aspectos problemáticos do MROSC, segundo os autores, são (a) a preservação da lógica burocrático-formal: ao estabelecer diversas obrigações de meios às OSCs, o MROSC inviabilizaria, na prática, a ênfase que deve ser dada ao controle de resultados, fazendo com que o controle de meios possa eclipsar o controle de resultados - algo que, segundo os autores, ocorre no âmbito da Lei n. 9.637/1998 -, (b) a manutenção de focos de insegurança jurídica: o MROSC não teria avançado no sentido de racionalizar a atuação dos órgãos de controle, isso porque institui a Comissão de Monitoramento e Avaliação, mas nada impede que a decisão ou orientação dada por

25 OlIVEIRA, Gustavo Henrique Justino de; FERREIRA, Carolina Filipini. Parcerias do Estado com o Terceiro Setor: impacto da Lei n. 13.019/2014 sob o enfoque da Insegurança Jurídica e Instabilidade das relações. Disponível em: http://www.justinodeoliveira.com.br/site/wp-content/uploads/2015/12/ ARTIGO_Parcerias-do-Estado-com-o-Terc-eiro-Setor_Impacto-da-Lei-n.-13019.14-sob-o-enfoque-daInseguranc\% $\%$ CC\%A7a-Juri\%CC\%81 dica-e-Instabilidade-das-relac\%CC\%A7o\%CC\%83es_GJO.pdf. Acesso em: 5 jun. 2019. 
esta Comissão seja posteriormente questionada pela Controladoria-Geral da União (CGU) ou Tribunal de Contas da União (TCU), (c) a tendência de padronização das parcerias: a excessiva regulamentação das parcerias por parte do MROSC teria deixado pouco espaço para que as OSCs, em parceria com o Poder Público, possam criar outras formas de arranjos contratuais que atendam mais adequadamente ao objeto da parceria. (DORA; PANNUZIO, 2013, p. 21-26).

Dessa forma, percebe-se que a doutrina administrativista tem demonstrado preocupação com a aptidão de o novo regime das parcerias com o Terceiro Setor ser, de fato, capaz de cumprir com os ditames do princípio da eficiência em razão de sua alta carga burocrática. Realmente, o MROSC procurou dar contornos mais claros aos procedimentos que devem ser seguidos para o planejamento, seleção, execução e controle das parcerias firmadas sob sua égide, porém acabou mantendo o viés altamente burocrático que já estava presente nas leis anteriores que regulavam as parcerias entre Poder Público e entidades do Terceiro Setor.

O MROSC traz instrumentos interessantes e inovadores que direcionam a execução das parcerias com as Organizações da Sociedade Civil no sentido de busca por maior eficiência e atingimento de resultados que sejam benéficos para a sociedade, assim como também procura esclarecer e pacificar pontos controversos que não eram tratados explicitamente pelos regimes legais anteriores e conferir maior segurança jurídica às Organizações da Sociedade Civil que firmarem parcerias com a Administração Pública. No entanto, o seu alto viés burocrático representa um risco que pode comprometer o atendimento ao princípio da eficiência e os objetivos traçados inicialmente pelo novo regime, de forma que somente o tempo será capaz de demonstrar claramente se tais instrumentos são suficientes para superar dificuldades que persistem durante longo tempo no campo das parcerias com o Terceiro Setor, visto que a entrada em vigor da Lei n. 13.019/2014 é consideravelmente recente. ${ }^{26} / 27$

São Paulo, junho de 2019.

\footnotetext{
26 A Lei n. 13.019/2014, após sucessivas prorrogações de sua vacatio legis, entrou em vigor em 23 de janeiro de 2016 para União e Estados, ao passo que, para os Municípios, a vigência do MROSC ocorreu somente em $1^{\circ}$ de janeiro de 2017.

27 Cf. Art. 88 da Lei n. 13.019/2014.
} 


\section{Referências}

ARAGÃO, Alexandre Santos de. O princípio da eficiência. In: MARRARA, Thiago (org.). Princípios do direito administrativo: legalidade, segurança jurídica, impessoalidade, publicidade, motivação, eficiência, moralidade, razoabilidade, interesse público. São Paulo: Atlas, 2012. p. 375 381.

BELEM, Bruno. O procedimento de manifestação de interesse social. In: MOTTA, Fabrício; MÂNICA, Fernando Borges; OLIVEIRA, Rafael Arruda (coord.). Parcerias com o terceiro setor: as inovações da Lei n. 13.019/14. Belo Horizonte: Fórum, 2017.

BRASIL. Decreto n. 8.726, de 27 de abril de 2016. Regulamenta a Lei n. 13.019, de 31 de julho de 2014, para dispor sobre regras e procedimentos do regime jurídico das parcerias celebradas entre a administração pública federal e as organizações da sociedade civil. Portal do Planalto, Brasília, DF., 2016. Disponível em: http:/www.planalto.gov.br/ccivil_03/_Ato2015-2018/2016/Decreto/ D8726.htm.

BRASIL. Lei n. 13.019, de 31 de julho de 2014. Estabelece o regime jurídico das parcerias entre a administração pública e as organizações da sociedade civil, em regime de mútua cooperação, para a consecução de finalidades de interesse público e recíproco, mediante a execução de atividades ou de projetos previamente estabelecidos em planos de trabalho inseridos em termos de colaboração, em termos de fomento ou em acordos de cooperação; define diretrizes para a política de fomento, de colaboração e de cooperação com organizações da sociedade civil; e altera as Leis ns. 8.429, de 2 de junho de 1992, e 9.790, de 23 de março de 1999. Portal do Planalto, Brasília, DF., 2014. Disponível em: http://www.planalto.gov.br/ccivil_03/_ato2011-2014/2014/lei/113019.htm. (Redação dada pela Lei n. 13.204, de 2015).

BUCCI, Maria Paula Dallari. Políticas públicas e direito administrativo. Revista de Informação Legislativa, Brasília, v. 34, n. 133, p. 89-98, jan./mar. 1997.

DI PIETRO, Maria Sylvia Zanella. Direito administrativo. 30. ed. Rio de Janeiro: Forense, 2017.

DI PIETRO, Maria Sylvia Zanella. Parcerias na administração pública. 11. ed. Rio de Janeiro: Forense, 2017.

DORA, Denise Dourado; PANNUZIO, Eduardo. Em busca da ousadia: comentários sobre o anteprojeto de lei apresentado pelo grupo de trabalho "Marco Regulatório das Organizações da Sociedade Civil”. In: LOPES, José Reinaldo de Lima Lopes. (coord.). Centro de Pesquisa Jurídica Aplicada. São Paulo: FGV, jun. 2013. p. 9-32. (Análise CPJA/DIREITO GV, n. 1).

FORTINI, Cristiana; CUNHA, Luana Magalhães de Araújo; PIRES, Priscila Giannetti Campos. O regime jurídico das parcerias voluntárias com as organizações da sociedade civil: inovações da Lei n. 13.019/2914. In: MOTTA, Fabrício; MÂNICA, Fernando Borges; OLIVEIRA, Rafael Arruda (coord.). Parcerias com o terceiro setor: as inovações da Lei n. 13.019/14. Belo Horizonte: Fórum, 2017. 
LAHOZ, Rodrigo Augusto Lazzari. De contas das organizações da sociedade civil: controle de meio ou de resultados? In: MOTTA, Fabrício; MÂNICA, Fernando Borges; OLIVEIRA, Rafael Arruda (coord.). Parcerias com o terceiro setor: as inovações da Lei n. 13.019/14. Belo Horizonte: Fórum, 2017.

LOPES, Laís Vanessa Carvalho de Figueirêdo; SOUZA, Silas Cardoso de; SANT'ANA, Diogo de; HERNANDEZ, Maria Victória; ARAUJO JÚNIOR, Evânio Antônio de; SOUZA, Aline Gonçalves de; MACEDO, Ana Túlia de. Fomento e colaboração: uma nova proposta de parceria entre Estado e Organizações da Sociedade Civil. Disponível em: http://www.secretariadegoverno.gov.br/.arquivos/ artigo_fomento-e-colaboracao. Acesso em: 5 jun. 2018.

MARQUES NETO, Floriano Peixoto de Azevedo. Noções gerais sobre o fomento estatal. In: DI PIETRO, Maria Sylvia Zanella (coord.). Tratado de direito administrativo: funções administrativas do Estado. São Paulo: Revista dos Tribunais, 2015. p. 405-428.

MARQUES NETO, Floriano Peixoto de Azevedo. Regulação estatal e interesses públicos. São Paulo: Malheiros, 2002.

MARTINS, Ricardo Marcondes. Acesso à informação e transparência nas parcerias voluntárias. In: MOTTA, Fabrício; MÂNICA, Fernando Borges; OLIVEIRA, Rafael Arruda (coord.). Parcerias com o terceiro setor: as inovações da Lei n. 13.019/14. Belo Horizonte: Fórum, 2017. p. 263-298.

MENDES, Guilherme Adolfo dos Santos. Princípio da eficiência. In: MARRARA, Thiago (org.). Princípios do direito administrativo: legalidade, segurança jurídica, impessoalidade, publicidade, motivação, eficiência, moralidade, razoabilidade, interesse público. São Paulo: Atlas, 2012. p. 352361.

OLIVEIRA, Gustavo Henrique Justino de. Contrato de gestão. São Paulo: Revista dos Tribunais, 2008.

OLIVEIRA, Gustavo Henrique Justino de; FERREIRA, Carolina Filipini. Parcerias do Estado com o Terceiro Setor: impacto da Lei n. 13.019/2014 sob o enfoque da Insegurança Jurídica e Instabilidade das relações. Disponível em: http://www.justinodeoliveira.com.br/site/wp-content/ uploads/2015/12/ARTIGO_Parcerias-do-Estado-com-o-Terc-eiro-Setor_Impacto-da-Lei-n.13019.14-sob-o-enfoque-da-Inseguranc\%CC\%A 7a-Juri\%CC\%81dica-e-Instabilidade-dasrelac\%CC\%A7o\%CC\%83es_GJO.pdf. Acesso em: 5 jun. 2019.

OLIVEIRA, Rafael Arruda. O chamamento público na Lei Federal n. 13.019/14: procedimento legal, avanços e retrocessos. In: MOTTA, Fabrício; MÂNICA, Fernando Borges; OLIVEIRA, Rafael Arruda (coord.). Parcerias com o terceiro setor: as inovações da Lei n. 13.019/14. Belo Horizonte: Fórum, 2017.

PEREIRA, Luiz Carlos Bresser. A reforma do estado dos anos 90: lógica e mecanismos de controle. Brasília: Ministério da Administração Federal e Reforma do Estado, 1997. (Cadernos MARE da reforma do estado; v. 1). 
RAMOS, Dora Maria de Oliveira. Princípio da eficiência. In: DI PIETRO, Maria Sylvia Zanella; RAMOS, Dora Maria de Oliveira; SANTOS, Márcia Walquiria Batista dos; D’AVILA, Vera Lúcia Machado. Temas polêmicos sobre licitações e contratos. 5. ed., revista e ampliada São Paulo: Editora Malheiros, 2006. p. 46-49.

SOUZA, Leandro Marins de. O Plano de trabalho na Lei n. 13.019/2014. In: MOTTA, Fabrício; MÂNICA, Fernando Borges; OLIVEIRA, Rafael Arruda (coord.). Parcerias com o terceiro setor: as inovações da Lei n. 13.019/14. Belo Horizonte: Fórum, 2017.

SOUZA, Rodrigo Pagani de. Em busca de uma Administração Pública de resultados. In: PEREZ, Marcos Augusto; SOUZA, Rodrigo Pagani de (coord.). Controle da administração pública. Belo Horizonte: Fórum, 2017.

SUNDFELD, Carlos Ari; ROSILHO, André. Direito e políticas públicas: dois mundos? In: SUNDFELD, Carlos Ari; ROSILHO, André (org.). Direito da regulação e políticas públicas. São Paulo: Malheiros, 2014.

SUNDFELD, Carlos Ari; SOUZA, Rodrigo Pagani de. As modernas parcerias públicas com o Terceiro Setor. $A \& C$ : Revista de Direito Administrativo \& Constitucional, Belo Horizonte, v. 11, n. 43, p. 57-90, jan./mar. 2011. 